\title{
A TÉCNICA ANALITICA DE GRUPO APLICADA À PESQUISA DA MOTIVAÇÃO
} MICHEL CARACUSHANSKY

\begin{abstract}
"Na comunicação muderna nós temos que explorar os significados mais frofundos que os indivíduos atribuem aos produtos, serviços e objetos que os cercam. Sòmente através dessa indági zção podemos realizar uma comunicação verdadeiramente efetiva e criadora." - ERNEST DICHTER
\end{abstract}

Uma das implicação da política econômica implantada no país pelo então Ministro Roberto Campos obrigou a reformulação da política de comunicação das emprêsas como condição indispensável de sobrevivência em um mercado que, repentinamente, deixou de ser o local eufórico onde bens e serviços eram transacionados sem maior preocupações, tanto da parte dos vendedores, seguros de que os seus preços nunca seriam demasiadamente elevados e os seus preços nunca seria demasiadamente elevados e suas suas margens de lucro nunca comprometedoramente altas, como por parte dos compradores, que abdicavam de bom grado do exercício de qualquer relacionalidade no ato de compra, certos de que os preços de hoje seriam inevitàvelmente inferiores aos da manhã e que os salários em breve sofreriam majoração que permitiriam saldar dívidas, em princípio, impossíveis de serem pagas.

Durante os anos que precederam êste esquema econômico, quando a inflação grassava impunemente e sustentava um

Michel Caracushansky - Consultor de Marketing em São Paulo, e Diretor de Pesquica Qualitativa da Consumer Panel do Brasil - Tendências do Mercado Ltda. 
mercado comprador atuante, bastava a muitas emprêsas produzir e suprir ràpidamente a avidez dos mercados consumidores.

A inversão que então ocorreu no mercado - de mercado vendedor para comprador — permitiu comprovar a ausência de um diálogo efetivo entre a indústria e seus consumidores em inúmeros setores. Verbas vultosas para propaganda eram comumente malbaratadas segundo os caprichos estéticos do gerente de propaganda, ou do corpo diretivo da emprêsa, apenas para justificar aos clientes distribuidorєs e varejistas a presença de marca nos veículcs de divulgação audio-visual. A mensagem jamais chegava a motivar o consumidor, cujas necessidades, desejos e preferências eram totalmente ignoradas pela indústria

As dificuldades surgidas no mercado de bens de consumo fizeram com que número maior de emprêsas passasse e se interessar pelas necessidades e desejos do consumidor de modo a capitalizar para os produtos da emprêsa uma parcela maior da preferência do público.

\section{LIMITAÇÕES DA PESQUISA ESTATÍSTICA CONVENCIONAL}

Habitualmente, a consulta ao consumidor realiza-se por meio de questionários pré-testados, que são distribuídos a entrevistadores treinados, os quais percorrem roteiros pré-estabelecidos a fim de investigar uma amostra probabilística da população, prèviamente selecionada mediante o emprêgo de métodos estatísticos específicos. $O$ entrevistador limita-se a transcrever as respostes do consumidor às perguntas do questionário.

Os questionários preenchidos são tabulados e analisados, e daí se conclui em que faixas de idade, escolaridade, classe sócio-econômica, estado civil, sexo, etc., situam-se os consumidores de determinada marca de produto, freqüência com que consomem êste produto, a proporção dêsses consumidores em relação aos das marcas concorrentes, os mo- 
tivos pelos quais determinados consumidores optaram por determinadas marcas, a probabilidade de que se mantenham leais à opção feita, as preferências pessoais quanto ao uso do produto, a reação do consumidor à determinadas mensagens de propaganda, etc.

A pesquisa do consumidor veio reatar o elo perdido entre muitas emprêsas o seus consumidores. Veio restabelecer o diálogo indispensável entre o produtor e o consumidor. Veio nortear a indústria no desenvolvimento de novos produtos, e na comunicação de novos apelos para o consumo dos produtos já existentes. A pesquisa do consumidor veio, inclusive, verificar com que eficácia êsse novos apelos eram comunicados ao consumidor e avaliar os resultados obtidos pelo investimento realizado em cada campanha de propaganda.

Verificou-se, entretanto, que muitas vêzes a entrevista direta de consumidor provoca uma reação inibitória no entrevistado, o que causa um efeito distorsivo nos resultados da pesquisa. Êsses resultados são invalidados particularmente quando se procura investigar um dos problemas magnos da indústria: - Por que determinados consumidores insistem em preferir os produtos dos concorrentes?

Os motivos pelos quais o ser humano se decide por êste ou aquêle produto não são apenas racionais e objetivos: geralmente, estão ìntimamente ligados a um complexo de sentimentos e emoções. Muitas vêzes, êsses motivos estão tão profundamente encobertos, que o próprio consumidor os ignora conscientemente, e é incapaz de descobri-los, embora esteja fazendo um esfôrço realmente sincero para explicar as sua próprias preferência e os seus hábitos de consumo. Daí a necessidade de utilizarmos técnicas indiretas mais requintadas para suplementar a pesquisa puramente estatística do consumidor.

O PAPEL DA PESQUisA DE MOTIVAÇÃO

A pesquisa da motivação do consumidor utiliza-se de ténicas específica, oriundas da psicologia, da psicanálise e das ciências comportamentais, para averiguar as razões 
reais que impelem os consumidores e elegerem determinada marca ou tipo de produtos.

As técnicas mais comumente empregadas na pesquisa da motivação são adaptação do T.A.T. (Thematic Apperception Test) de H. A. MurRay e C. D. Morgan, do P.F.T. (Picture Frustration Test) de S. Rosenweig, do psicodrama de J. L. Moreno, da técnica analítica de grupo de W. R. Bron, além de outras.

Êste artigo relata a aplicação de uma dessas técnicas a analítica de grupo - em um programa de pesquisas realizadas pelo autor, que permitiu à emprêsa contratante a obtenção de informações indispensáveis para reformular as diretrizes então em vigor nos setores de promoção de vendas, de propaganda e relações públicas.

Posteriormente, dada a originalidade de alguns aspectos interpretados na pesquisa, êste trabalho foi apresentado e debatido na III Jornada Brasileira de Psicoterapia de Grupo, realizado no Instituto de Psicologia da Universidade do Brasil, no Rio de Janeiro, sob o patrocínio da Sociedade Brasileira de Psicoterapia de Grupo, da Sociedade Paulista de Psicologia e Psicoterapia de Grupo e da Sociedade de Psicoterapia de Grupo de Pôrto Alegre.

É significativo o fato de que esta pesquisa da motivação foi precedida por uma série exaustiva de investigações de campo, cujos resultados permitiram configurar todo o panorama estatístico do mercado consumidor: hábitos de compra, hábitos de consumo, sabor, imagem do produto, imagem do consumidor etc. Todos êsses dados foram fornecidos com discriminação, por sexo, idade, classe social, cidade, marca, local da compra, tipo de embalagem, preço de varejo, horário de consumo, etc.

Essa bagagem estatística nos oferecia tôdas informações de quanto, quando e onde; mas não nos revelava o porquê de tais fatos. Por exemplo: a pesquisa estatística foi capaz de medir a influência da imagem negativa do produto em números porcentuais; contudo, foi incapaz de revelar o porquê đêsse deficit de imagem ou corno corrigi-lo. 
O objetivo da pesquisa motivacional é precisamente êsse: compreender as motivações responsáveis pelos fatos verificados na pesquisa estatística, a fim de determinar providências corretivas.

Por isso o emprêgo da pesquisa de motivação justificou-se uma vez exauridos os demais recursos para a solução dos problemas constatados. Sua finalidade precípua foi complementar e interpretar os dados prèviamente colhidos na pesquisa estatística convencional.

\section{A TECNICA ANALÍtica DE GRUPO}

Com a finalidade de tornar a psicanálise accessível a um maior número de pessoas, surgiu a técnica analítica de grupo, que é a aplicação do método psicanalítico freudiano ao tratamento de pacientes em grupo.

Seu precursor, o psicanalista inglês W. R. BIoN, fundamentando-se em pesquisas realizadas no âmbito da sociologia, da psicologia social e da Gestalt, partiu da conceituação do grupo como unidade psicológica. Considerandose o paciente-grupo como um único indivíduo, tornou-se possível utilizar a técnica psicanalista freudiana, originalmente estruturada para o atendimento individual.

BIon reunia grupos de pacientes em seu consultório, aos quais facultava falar do que lhes aprouvesse, assumir as atitudes que preferissem, escolher os seus lideres, sem que Bron interferisse de forma alguma no comportamento dos grupos. BION ouvia a variedade de assuntos discutidos, que representavam uma associação livre de idéias e, através do denominador comum dos diversos temas apresentados, procurava compreender o que ocorria no plano inconsciente grupal. Percebeu, então, que não só o conteúdo das palavras, mas também a sua forma, as atitudes do grupo e a distribuição dos participantes na sala, podiam conduzi-lo a deduções sôbre as necessidades, as ansiedades e as motivações não-consciențes do grupo. BIoN limi- 
tava-se a apontar os conteúdos inconscientes à medida que se manifestavam, sem violar a resistência oposta pelo grupo. Eximia-se de qualquer julgamento ético, isto é, de rotular aquêles conteúdos como "bons" ou "maus", "certos" ou "errados", como também abstinha-se de opinar, sugerir ou liderar.

A finalidade precípua dos trabalhos de BIoN era possibilitar ao grupo a tomada de consciência dos mecanismos inconscientes, a qual situaria corretamente o grupo frente aos seus objetivos e aos obstáculos internos que se opõem à consecução dos mesmos.

O que resulta fundamentalmente nos trabalhos de Bion é que indivíduos grupados em determinado momento, num mesmo local, com uma finalidade em comum, apresentam, infalìvelmente, uma série de necessidades psicológicas idênticas. $E$ que, num grupo que se estrutura sem interferência externa só pode afluir um tipo de comportamento que atenda à necessidade grupal sob algum aspecto.

Se a técnica analítica de grupo com finalidade especificamente terapêutica deve restringir-se à interpretação dos mecanismos grupais, já a adaptação. da técnica para fins não-terapêuticos - como, por exemplo, a pesquisa da motivação - exige que verifiquemos a adequação das hipóteses tanto no plano grupal como no plano individual de cada participante, pois essa correspondência entre os dois planos é uma das formas de validação das hipóteses que se pretende fundamentar na pesquisa.

A técnica analítica de grupo adaptada à pesquisa da motivação tem sido utilizada muito raramente no Brasil em virtude das dificuldades que apresenta para uma manipulação profícua. Seu precursor, ERNEST Dichter, da escola de Viena, responsável pela paternidade de tôda uma corrente de pesquisa da motivação aplicada aos problemas mercadológicos, foi quem cunhou o nome pelo qual essa técnica é conhecida nos círculos leigos: depth group interview (entrevista de profundidade em grupos). 
Descrição da Pesquisa

Na primeira etapa do nosso programa de pesquisa - que é a única que iremos focalizar neste trabalho - investigou-se uma das motivações básicas da mulher: a de saciar a fome de sua prole. Essa pesquisa teve lugar na Capital de São Paulo, onde contou com a colaboração do "EMAI - Instituição de Estudos para a Mulher" e da "Escolinha Walita", que nos facultaram a entrevista de grupos de senhoras que participavam dos cursos regulares daquelas entidades.

A aplicação da técnica analítica de grupo foi realizada pelo autor. As sessões foram gravadas em fita, e sua reprodução posterior permitiu a supervisão dêste trabalho pori duas psicólogas-clínicas, ARACI MARTINS Rodrigues e Sofia CaRACushansky, ambas de formação psicanalítica.

$\mathrm{Na}$ composição dos grupos desprezamos os fatôres objetivos, tais como as características demográficas de indivíduo (idade, côr, estado civil, profissão, escolaridade, etc.), tradicionalmente consagradas pelos estatísticos.

Para a composição do grupo utilizamos um critério que reuniu, dentro do mesmo grupo, mães de família que apresentavam as mais diversas atitudes em relação à motivação específica que foi objeto desta pesquisa, isto é, em relação à motivação de saciar a fome da prole. Assim, estruturamos grupos heterogêneos constituídos de:

- individuos que jamais satisfizeram essa motivação;

- indivíduos que já satisfizeram essa motivação, mas não o fazem mais;

- indivíduos que satisfazem ocasionalmente essa motivação;

- indivíduos que satisfazem regularmente essa motivação;

- individuos que satisfazem compulsivamente essa motivação. 
O número de componentes de cada grupo variava de 6 a 11 participantes. As participantes que integraram os diversos grupos foram convidadas - por um elemento auxiliar - a participar de uma discussão em grupo sôbre os problemas que interessam à mulher dos nossos dias. Antes do início de cada sessão, as participantes receberam uma circular mimeografada que sugeria, de forma muito generalizada, alguns temas dentro da área de interêsse para essa pesquisa.

Bastaria esta situação, sem paralelo na situação terapêutica, para justificar as variações na aplicação da técnica analítica de grupo ao desenvolvimento dêste trabalho.

As sessões se prolongavam de duas a três horas, com a presença de um coordenador do grupo.

Tal como na situação terapêutica, o coordenador do grupo aqui tampouco lidera: interfere o mínimo possivel, pois a sua função precípua é interpretar o material apresentado em nível, geralmente consciente, e, às vêzes, inconsciente.

Contudo, diversamente da situação terapêutica, o coordenador encoraja a participação ativa de todos os componentes do grupo, evitando assim que os mais extrovertidos monopolizem as sessões em detrimento dos mais introvertidos, e ainda impede que os temas em pauta descambem para áreas irrelevantes ou suscitem diálogos simultâneos.

Todavia, a maior diferença da situação terapêutica está no fato de o coordenador do grupo não fazer uso intensivo da interpretação transferencial, uma vez que não há interêsse que o grupo conheça a correlação entre a Vivência da Situação Terapêutica do aqui, do agora e os seus conflitos passados, pois tal procedimento poderia trazer à tona um material que só valeria para aquela determinada situação naquele determinado momento, e pouco esclarecer quanto à motivação que nos propusemos pesquisar. Algumas interpretações transferenciais foram, entretanto, trans- 
mitidas ao grupo a fim de resolver certas dificuldades de comunicação grupal.

À medida em que a discussão do grupo evolui, as participantes passaram de uma relação formal para uma relação grupal autêntica, na qual o coordenador do grupo e o grávador de som eram incorporados à realidade vivida pelo grupo, passando a fazer parte integrante do todo.

O coordenador responsável pela realização das entrevistas de profundidade nessa pesquisa é o autor dêste artigo, que recebeu 230 horas de treinamento em um grupo de psicoterapia analítica antes de entregar-se a pesquisas de tal natureza.

\section{Análise dos Resultados}

Entre os resultados obtidos na pesquisa, destacamos os seguintes:

1. A identificação da mulher com o alimento - Ao realizar uma das funções mais autênticas - que é a de procriar - a mulher gera dentro de si, simultâneamente, o futuro ser e a sua alimentação. Tanto um como outro são sentidos por ela como extensões do seu próprio corpo. Finda a gestação, o rebento se desprende do organismo materno, mas regressa a êle constantemente para sorver a sua subsistência. Ao amamentá-lo, a mulher sente que o provê ainda com uma parte de si mesma. Numa fase posterior, as mãos passam a ser sentidas pela mulher como um prolongamento do próprio seio. Ela sente os alimentos "criados" por suas mãos como sendo ela mesma, quase tanto quanto o leite que ela gera.

2. A existência de um processo evolutivo que vai afastando gradativamente a mulher das suas funções mais genuínas e criadoras - Com o advento da Revolução Industrial, a mulher foi afastada das fontes de alimentação e compelida a permitir que outras mãos substituissem as suas nas fases preliminares da preparação dos alimentos: é o laticínio que se encarrega de mungir a vaca e preparar a manteiga e o queijo, é a panificadora que cozinha o 
pão, é o pastifício que prepara as massas com ovos, é a torrefação que se encarrega de torrar e moer o café, etc. Contudo, a mulher insiste em personalizar êsses alimentos, prèviamente elaborados, mediante a diversificação de requintes "criativos": as massas alimentícias "artificiais" são "enriquecidas" com môlhos segundo receita especial, as sopas desidratadas são "enriquecidas" com ingredientes naturais que ela adiciona em quantidades e variedades ao sabor dos seus caprichos criativos, o café já torrado e moído é "criativamente" coado, escaldado, servido... Ainda nesta fase, mesmo quando a mulher admite que suas mãos sejam totalmente substituídas pelas da cozinheira, ela jamais relegará a outrem o privilégio de "enriquecer a refeição com as "honras da mesa", na qual ela se afirma como "dona" indiscutível da comida.

Porém, o processo evolutivo prossegue, levando a mulher a substituir os alimentos anteriores semi-elaborados, por outros totalmente pré-elaborados, tais como a maionese, o café solúvel, e a sopa desidratada que não admite a inclusão de ingredientes adicionais e nem a intrusão dos caprichos criativos da mulher. Não podendo participar da "criação" dêsses alimentos, sente que êles deixam de "ser ela" para ser algo capaz de substitui-la.

3. A rejeição da mulher aos alimentos que ameaçam súbstituti-la - A fim de justificar sua rejeição aos alimentos "usurpadores", a mulher apresenta uma série de racionalizações como o fato de serem produtos de origem desconhecida, elaborados por pessoas inescrupulosas, de valor nutritivo duvidoso, nocivos à saúde, etc.

$\mathrm{Na}$ verdade, a mulher sente qúe êsses alimentos "auto-suficientes" vêm questionar a própria razão de sua existência como mãe fértil e provedora, e ameaçam despojá-la dêsse pôsto, no qual ela exerce a sua função mais autêntica, que é a única capaz de redimi-la de sua desvalorização frente ao homem.

4. Da auto-rejeição à auto-suficiência da mulher Quando a mulher amamenta, ou quando "cria" um alimen- 
to que é ingerido pelos demais, ela satisfaz a sua necessidade psicológica de penetração somática. Quando, entretanto, a mulher se vê compelida a adotar produtos substitutivos, que não lhe oferecem essa oportunidade, ela sente-se impotente e castrada. Diante dessa contingência, ela opta por uma das seguintes alternativas:

- rejeita os produtos "auto-suficientes" por não lhe oferecerem oportunidade de penetração (essa rejeição tende a atenuar-se quando êsses produtos apresentam uma imagem fálica);

- não rejeita os produtos "auto-suficientes", mas ela própria torna-se autc-suficiente ao renunciar à criatividade doméstica para assumir atividades mais fecundas e viris; na medida em que substitui o homem nas funções tradicionalmente masculinas, ela pode permitir-se, também, ser substituída pelos produtos substitutivos, pois não mais teme ser desalojada do seu pôsto de mãe provedora - e assim perder a sua identidade - porque agora ela está habilitada a ocupar um nôvo pôsto no seio da nova estrutura social.

5. A ambivalência da mulher na fase de transição da criatividade doméstica para a emancipação social - A mulher em fase de emancipação ainda não renunciou totalmente ao seu papel de mãe provedora. Ela mantém um pé em cada pôsto: ela aceita e não aceita ao mesmo tempo o produto substitutivo, pressionada por um Super-Ego que não admite que seu bem-estar fique em primeiro plano. Essa ambivalência resulta na aceitação por parte da mulher do produto substitutivo, desde que êsse possa ocultar ou justificar essa substituição através de uma racionalização. A mulher revela que usa produtos substitutivos, mas pouco frequientemente, em ocasições especiais, em circunstâncias excepcionais, em situações de emergência. Atribuindo um pretenso cunho de excepcionalidade aos seus "deslizes" a favor de alimentos "facilitadores", a mulher consegue desfrutá-los sem ter de renunciar à velha imagem idealizada de mãe provedora. $O$ entusiasmo da mulher por tais produtos será tanto maior quanto mais 
verossímil e altruística fôr a racionalização que êstes lhe puderem oferecer Assim sendo, a mulher exige que o produto "facilitador" the ofereça ora a racionalização dignificante da saudabilidade, ora da aprovação familiar, ora da adesão à maioria, ora do conteúdo nutritivo.

CONSIDERAÇÕES FINAIS

O critério de validação desta pesquisa é o mesmo que tem sido utilizado na validação de conceitos psicanalíticos. A êsse respeito citamos aqui o trabalho "Métodos de Objetivação na Investigação Psicanalítica" de WILLy BARANGER, tema oficial do II Congresso Psicanalítico LatinoAmericano, onde foram examinadas as formas possíveis de fundamentação dos conhecimentos analíticos. $O$ ideal de objetivação, para a grande maioria dos autores, consiste em validar tais conhecimentos nos domínios científicos extra-analíticos. Para BARANGer isto implica no abandono da metodologia própria, que passa a ser substituída pelos critérios de prova das ciências físicas e biológicas. Afirma que cada uma das ciências não pode ser comprovada ou infirmada pelas demais. Em psicologia fracassa, necessàriamente, a consideração de um determinismo causal semelhante ao biológico. Restaria um único caminho, derivado da característica essencial da psicanálise, que é a interpretação dentro da situação analítica. $A$ interpretação está fundamentada na teoria e, portanto, se ela atinge seu objetivo, isto é, se consegue provocar modificações no grupo, a sua fundamentação teórica é válida.

Seguindo o critério proposto por BARANGER, só computamos as conclusões que, quando transmitidas ao grupo, atingiram seu objetivo, trazendo modificações no comportamento do grupo ou reações violentas de surprêsa, revolta, hilaridade, etc., tal como pode ser constatado na audição das fitas gravadas durante as sessões que fundamentaram êste trabalho.

Contudo, além dêste critério validativo intrínseco, utilizamos ainda métodos de validação complementares, tais como as pesquisas estatísticas realizadas a priori e os tes- 
tes projetivos aplicados a posteriori (TAT, PFT, Psicodrama), os quais vieram comprovar estatìsticamente os mesmos aspectos já validados anteriormente.

Uma vez concluída a validação da análise, seguiu-se a segunda fase da pesquisa - a síntese — na qual nos empenhamos em recompor as unidades desmembradas na fase analítica a fim de devolvê-las ao inconsciente do consumidor sob a forma de purchase propositions (mensagens motivadoras) específicas para o produto que foi objeto da pesquisa. Esta segunda etapa também é criativa, pois exige a participação de um layout man na criação de roughs (esboços) representativos de cada uma dessas mensagens, a fim de aferirmos quantitativamente, através do $R e-$ lative Sales Conviction Test, qual delas melhor motiva o consumidor às reações desejadas; a mais eficaz delas norteará os trabalhos definitivos dos departamentos de arte e redação de agência de propaganda. O autor absteve-se de comentar mais longamente os trabalhos realizados nesta etapa da pesquisa a fim de proteger, evidentemente, a discreção profissional que cerca as atividades desta natureza.

Finalmente, em uma terceira etapa, propuzemos a programação de uma verificação periódica capaz de aferir a eficácia com que a mensagem eleita na fase anterior é comunicada ao público. Este contrôle é realizado por meio de pesquisas estatísticas com amostras probabilísticas da população segundo os princípios estabelecidos pela ANA (Association of National Advertisers, Inc.) em 1961, como resultado do muito celebrado projeto que determinava os métodos para quantificação da rentabilidade dos investimentos em propaganda. 